\title{
Thermoresponsive and Conductive Chitosan-Polyurethane Biocompatible Thin Films with Potential Coating Application
}

\author{
Junpeng $X u^{1}$, Chih-Yu Fu ${ }^{1}$, Yu-Liang Tsai ${ }^{1}$, Chui-Wei Wong ${ }^{1}$ and Shan-hui Hsu ${ }^{1,2, *(D)}$ \\ 1 Institute of Polymer Science and Engineering, National Taiwan University, No. 1, Sec. 4 Roosevelt Road, \\ Taipei 10617, Taiwan; f07549033@ntu.edu.tw (J.X.); r07549005@ntu.edu.tw (C.-Y.F.); \\ jimmy821212@gmail.com (Y.-L.T.); caryn1111@gmail.com (C.-W.W.) \\ 2 Institute of Cellular and System Medicine, National Health Research Institutes, No. 35 Keyan Road, \\ Miaoli 35053, Taiwan \\ * Correspondence: shhsu@ntu.edu.tw; Tel.: +886-2-3366-5313; Fax: +886-2-3366-5237
}

Citation: $\mathrm{Xu}, \mathrm{J} . ; \mathrm{Fu}, \mathrm{C.-Y}$.; Tsai, Y.-L.; Wong, C.-W.; Hsu, S.-h. Thermoresponsive and Conductive Chitosan-Polyurethane

Biocompatible Thin Films with Potential Coating Application. Polymers 2021, 13, 326. https:// doi.org/10.3390/polym13030326

Received: 20 November 2020

Accepted: 18 January 2021

Published: 20 January 2021

Publisher's Note: MDPI stays neutra with regard to jurisdictional claims in published maps and institutional affiliations.

Copyright: (C) 2021 by the authors Licensee MDPI, Basel, Switzerland. This article is an open access article distributed under the terms and conditions of the Creative Commons Attribution (CC BY) license (https:// creativecommons.org/licenses/by/ $4.0 /)$

\begin{abstract}
Conductive thin films have great potential for application in the biomedical field. Herein, we designed thermoresponsive and conductive thin films with hydrophilicity, strain sensing, and biocompatibility. The crosslinked dense thin films were synthesized and prepared through a Schiff base reaction and ionic interaction from dialdehyde polyurethane, N-carboxyethyl chitosan, and double-bonded chitosan grafted polypyrrole. The thin films were air-dried under room temperature. These thin films showed hydrophilicity and conductivity (above $2.50 \mathrm{mS} / \mathrm{cm}$ ) as well as responsiveness to the deformation. The tensile break strength (9.72 $\mathrm{MPa}$ to $15.07 \mathrm{MPa}$ ) and tensile elongation (5.76\% to $12.77 \%$ ) of conductive thin films were enhanced by heating them from $25{ }^{\circ} \mathrm{C}$ to $50{ }^{\circ} \mathrm{C}$. In addition, neural stem cells cultured on the conductive thin films showed cell clustering, proliferation, and differentiation. The application of the materials as a conductive surface coating was verified by different coating strategies. The conductive thin films are potential candidates for surface modification and biocompatible polymer coating.
\end{abstract}

Keywords: conductive thin film; thermoresponsive; polyurethane; chitosan; biocompatibility; polymer coating

\section{Introduction}

Conductive polymers are considered to be a class of organic materials having electric and optical properties. The conductivity of such materials comes from different types of electric charges, which are the conjugated $\pi$ system, conductive nanomaterials, conductive polymers, and ions [1,2]. Among different forms of conductive polymers, conductive films hold the advantages of having short processing time, low manufacturing price, and industrially scalable potential [3-5]. Moreover, conductive films are versatile so they can be designed and applied in biosensors, flexible electronics, neural regeneration, antifouling coating, wearable electronics, and optoelectronic devices [4,6-10], depending on various selections of materials. Meanwhile, the functionalization of a few common film-forming materials (e.g., polyurethane [11] and chitosan [12]) may be the key to a breakthrough of the preparation for multifunctional films.

Polyurethanes, consisting of hard and soft segments, are a class of polymeric materials with tunable mechanical properties, firm chemical resistance, and stable heat insulation $[3,13,14]$. Biodegradable waterborne polyurethanes, also possessing biocompatibility, are of particular interest for their environmentally friendly process and impact $[3,15]$. Polyurethane films, as a kind of classic products, have a wide range of applications, including for gas barriers, flame retardants, electromagnetic interference shielding, and nerve conduits $[13,14,16,17]$. Additionally, polyurethanes can be modified to have different functionalities by changing the soft segments or end groups, making polyurethanes thermoresponsive, photosensitive, or crosslinkable [18-20]. A crosslinkable waterborne 
polyurethane, dialdehyde polyurethane (DAPU), has been developed recently to broaden the horizon for combining synthetic polymers with natural polymers [20]. With the abovementioned development, the applications of polyurethane-based materials are expected to integrate more functions together and be further expanded from classic synthetic polymers to multifunctional biomedical applications.

Chitosan is a linear and cationic polysaccharide derived from the exoskeleton of crustaceans and it is non-toxic, stable, biodegradable, and sterilizable [21,22]. Chitosan can be chemically modified with different stimulus-response moieties because of its molecular structure of D-glucosamine and $\mathrm{N}$-acetylglucosamine (e.g., $\mathrm{N}$-carboxyethyl chitosan (CEC) [23], glycol chitosan [24]). Moreover, chitosan demonstrates film-forming properties and is primarily utilized in food packing and biomedical applications [5]. Chitosan films exhibit good biocompatibility and antimicrobial property $[25,26]$. Upon adding conductive elements, chitosan films can be designed to possess an electrical conductivity near native tissues and regulate the differentiation of stem cells $[2,8,27]$. Therefore, chitosan along with conductive elements are anticipated to open a new frontier in wound healing and tissue engineering.

Recently, a hydrated conductive hydrogel/scaffold with three-dimensional porous structure and needle injectability was developed [28]. Conductive nanoparticles (i.e., double-bonded chitosan grafted polypyrrole, DCP) used in the earlier work showed good biocompatibility and considerable conductivity. However, such a hydrogel/scaffold can only be used under a hydrated state to present various properties. Most chitosanbased hydrogels, including the one published earlier [28], are brittle after drying, while conductive films need to keep favorable physical properties and biocompatibility in the dried state. Therefore, this is a new attempt to develop a biodegradable conductive film with low brittleness and coating possibility. In the present study, we aim to develop a multifunctional two-dimensional thin film combining DAPU nanoparticles, CEC, and DCP, which can be used under dry conditions and maintain adequate conductivity. Such thin films, crosslinking the two chitosan derivatives with DAPU, are obtained under room temperature and are expected to possess various functions such as strain sensing and thermal responsiveness. The potential functionality and application of the conductive thin film as a biocompatible polymer coating strategy are evaluated.

\section{Materials and Methods}

\subsection{Materials}

Poly( $\varepsilon$-caprolactone) diol (PCL, Mn 2000 Da, Sigma-Aldrich, St. Louis, MO, USA), isophorone diisocyanate (IPDI, Acros, Geel, Belgium), Sn(Oct) 2 (Alfa Aesar, Haverhill, MA, USA), 2,2-bis(hydroxymethyl) propionic acid (DMPA, Sigma-Aldrich, St. Louis, MO, USA), triethylamine (TEA, J.T. Baker, Phillipsburg, NJ, USA), ethylenediamine (EDA, Tedia, Fairfield, OH, USA), glyoxal (Alfa Aesar, Haverhill, MA, USA), chitosan (170 kDa, 97\% deacetylation, Kiotec, Hsinchu, Taiwan), acrylic acid (Showa, Gyoda, Japan), $\mathrm{NaOH}$ (Sigma-Aldrich, St. Louis, MO, USA), methacrylic anhydride (MAA, Sigma-Aldrich, St. Louis, MO, USA), acetic acid (Fluka, Buchs, Switzerland), pyrrole (Alfa Aesar, Haverhill, MA, USA), oxidant ammonium persulfate (APS, Sigma-Aldrich, St. Louis, MO, USA), $\mathrm{HCl}$ (Showa, Gyoda, Japan), high glucose Dulbecco's modified Eagle's medium (HGDMEM, Gibco, Waltham, MA, USA), fetal bovine serum (FBS, Gibco, Waltham, MA, USA), Ham's F-12 (Gibco, Waltham, MA, USA), G418 (Invitrogen, Waltham, MA, USA), penicillinstreptomycin-amphotericin (PSA, Caisson Laboratories, Inc., Smithfield, UT, USA), cell counting Kit-8 (CCK-8, Sigma-Aldrich, St. Louis, MO, USA), and KAPA SYBR Green qPCR kit (Kapa Biosystems, Inc., Wilmington, MA, USA) were applied in commercial form.

\subsection{Waterborne Synthesis of Dialdehyde Polyurethane Crosslinker (DAPU)}

DAPU was synthesized by the waterborne process through glyoxal termination of polyurethane in the final step of the polymerization, as detailed in our previous study [20]. For chemical synthesis, $10 \mathrm{~g}$ of PCL (soft segment) and $3 \mathrm{~g}$ of IPDI (hard segment) in a glass 
flask were reacted for $3 \mathrm{~h}$ with $0.05 \%$ catalyst $\mathrm{Sn}(\mathrm{Oct})_{2}$ at a nitrogen atmosphere of $75{ }^{\circ} \mathrm{C}$. Mass of $0.6699 \mathrm{~g}$ of DMPA (hard segment) and appropriate methyl ethyl ketone solvent were put into the flask under reflux and reacted for another hour. Afterwards, $0.505 \mathrm{~g}$ of TEA was added at $50{ }^{\circ} \mathrm{C}$ and reacted for $30 \mathrm{~min}$. Deionized distilled (DD) water was used to disperse the product followed by the reaction for $1 \mathrm{~h}$ with $0.21 \mathrm{~g}$ EDA (hard segment) as the chain extension agent. Finally, $0.5075 \mathrm{~g}$ of glyoxal was added and reacted for $30 \mathrm{~min}$ to form the dialdehyde polyurethane crosslinker dispersion. The stoichiometric ratio of oligodiol/IPDI/DMPA/EDA/glyoxal was 1:2.7:1:0.7:0.7.

\subsection{Synthesis of N-Carboxyethyl Chitosan (CEC)}

CEC was synthesized by functionalization of chitosan, as described in the previous literature [29]. To achieve the proper extent of functionalization, $4.0 \mathrm{~g}$ chitosan, $100 \mathrm{~mL} \mathrm{DD}$ water, and $2.88 \mathrm{~g}$ acrylic acid were put into a flask and reacted at $50{ }^{\circ} \mathrm{C}$ for $48 \mathrm{~h}$. The $\mathrm{pH}$ value of the CEC solution was adjusted to 7 with $1 \mathrm{M} \mathrm{NaOH}$ and dialyzed $(12,000-14,000$ MWCO) to remove unreacted substances or small molecules. Lastly, the CEC powder with a controlled degree of carboxyethyl functionalization was obtained by freeze-drying to remove water and stored at $-20^{\circ} \mathrm{C}$.

\subsection{Synthesis of Polypyrrole Modified with Double-Bonded Chitosan (DCP)}

The synthesis of nanoparticle DCP was based on the previous literature [28,30]. Chitosan was modified with MAA to produce double bond chitosan (DCS) as an intermediate. First of all, $2.14 \mathrm{~g}$ chitosan was slowly added to $50 \mathrm{~mL}$ of $2 \mathrm{wt} \%$ acetic acid. The chitosan solution was stirred for $2 \mathrm{~h}$ at $80^{\circ} \mathrm{C}$ and then cooled down to $25^{\circ} \mathrm{C}$. A total of $185 \mu \mathrm{L}$ aqueous MAA was added drop by drop to the chitosan solution and continuously stirred at a constant speed for $12 \mathrm{~h}$, dialyzed with DD water, and then freeze-dried to get pure DCS solid. DCS and pyrrole were polymerized by APS to prepare DCP dispersion. DCS (100 mg) was dissolved in $25 \mathrm{~mL} 0.1 \mathrm{M} \mathrm{HCl}$. Also, $578 \mu \mathrm{L}$ pyrrole was added to the DCS solution and stirred for $2 \mathrm{~h}$ at room temperature. APS $(0.19 \mathrm{~g})$ was added into the system slowly for $24 \mathrm{~h}$ and was neutralized to $\mathrm{pH}=7.4$ by $1 \mathrm{M} \mathrm{NaOH}$ solution to obtain the final DCP dispersion.

\subsection{Preparation of DAPU/CEC/DCP Thin Films (DCDFs)}

Various DCDFs were prepared by mixing CEC, DCP, and DAPU in the proper order to form a precursor. CEC aqueous solution should be mixed first with DCP, and then added with various concentrations of DAPU before vortex to obtain the uniform precursor. The precursor was poured into a Teflon dish (or other moulds) and removed of the remaining solvent at $25{ }^{\circ} \mathrm{C}$ to obtain the final DCDF.

\subsection{Physico-Chemical Characterization of DCDFs}

Surface contact angles were measured with an optical contact angle meter at ambient temperature. A sample $(80 \mathrm{~mm} \times 80 \mathrm{~mm})$ was put on the movable sample stage and levelled horizontally. DD water droplets were dropped carefully onto the surfaces, the average value of five measurements at different positions of the sample was adopted as the contact angle, and the angle changes were recorded versus time. The pyrolytic temperatures of all thin films were obtained using thermogravimetric analysis (TGA, Q50, TA Instruments Inc., New Castle, DE, USA) at a heating rate of $10^{\circ} \mathrm{C} / \mathrm{min}$ under a nitrogen atmosphere. Each sample was $5 \mathrm{mg}$ in weight. The melting temperature of various thin films was measured by differential scanning calorimetry (DSC, Q20, TA Instruments Inc., New Castle, DE, USA). Each sample was $5 \mathrm{mg}$ in weight and was placed in an aluminum mold. The operating temperature was elevated from $-80^{\circ} \mathrm{C}$ to $160^{\circ} \mathrm{C}$ at a rate of $5^{\circ} \mathrm{C} / \mathrm{min}$ under a nitrogen atmosphere. Melting temperatures $\left(T_{\mathrm{m}}\right)$ were obtained at the peak of the melting endotherms, and the enthalpies of fusion $\left(\Delta H_{\mathrm{m}}\right)$ were obtained from the areas under the peaks. The crystallinity degree $\left(X_{\mathrm{c}}\right)$ was determined by the equation $\Delta H_{\mathrm{m}} / \omega \cdot \Delta H_{\mathrm{m}}{ }^{0} \times 100 \%$, where $\Delta H_{\mathrm{m}}$ is the experimental melting enthalpy and $\omega$ is the 
weight fraction of material [31]. Additionally, it was assumed that the enthalpy of melting $\left(\Delta H_{\mathrm{m}}{ }^{0}\right)$ of $100 \%$ crystalline PCL and chitosan was $139 \mathrm{~J} / \mathrm{g}$ and $189 \mathrm{~J} / \mathrm{g}$, respectively [32]. The modulus of elasticity (Young's modulus) of each group was calculated by the equation $\sigma / \varepsilon$, where $\sigma$ was the tensile stress and $\varepsilon$ was the axial strain. The surface profiler (Surfcorder ET3000) was used to measure the two-dimensional surface roughness of thin films. The images of the cross-section and surface from the thin films were acquired using a scanning electron microscope (SEM, Hitachi TM 3000, Hitachi, Ltd., Tokyo, Japan) operated at a voltage of $5 \mathrm{kV}$. The mechanical properties of the thin film were tested by a stretching machine and a dynamic mechanical analyzer (DMA, Q800, TA Instruments Inc., New Castle, DE, USA). Dogbone-shaped tensile specimens were cut from the internationally regulated dumbbell cutter. Tensile tests were performed on a Tensilon (World Meteorology CO., Ltd., Taichung City, Taiwan) tensile tester, and the samples were pulled at a rate of $1 \mathrm{~mm} / \mathrm{min}$ under $25^{\circ} \mathrm{C}$ and $50^{\circ} \mathrm{C}$. The DMA was used to analyze the modulus of thin films at a rate of $1 \mathrm{~mm} / \mathrm{min}$ under $25^{\circ} \mathrm{C}$ and $50^{\circ} \mathrm{C}$.

\subsection{Strain Sensing Function of DCDFs}

The sensitivity of DCDF to multiple strains, including compression, bending, and twisting, was studied using a single-channel system source meter (2601B, Keithley Instruments, Inc., Cleveland, $\mathrm{OH}, \mathrm{USA}$ ) to receive the conductivity through the four-point probe under a voltage of $0.5 \mathrm{~V}$ at $25{ }^{\circ} \mathrm{C}$ dried environment. All the samples were cut to a single size $25 \mathrm{~mm} \times 10 \mathrm{~mm} \times 0.5 \mathrm{~mm}$ (length $\times$ width $\times$ thickness). The compressive stress was applied at a weight of $50 \mathrm{~g}$ on DCDF. The bending strain was given to the DCDF upon repeated bending from $90^{\circ}$ to $0^{\circ}$. With one end fixed, another end of the DCDF was twisted to the designed torsion angle $180^{\circ}$ to record the twisting strain. The conductivity changes were calculated by the formula $\Delta R / R_{0}=\left(R_{\mathrm{i}}-R_{0}\right) / R_{0}$, where $R_{\mathrm{i}}$ represents the real-time conductivity and $R_{0}$ represents the conductivity in the absence of strain [33].

\subsection{Cell Attachment and Proliferation Analysis}

Neural stem cells (NSCs) derived from the brain of adult mice were used for the cell culture test. The medium of NSCs was the HG-DMEM, which contained $10 \%$ FBS, Ham's F-12, $400 \mathrm{mg} / \mathrm{mL}$ G418, and 1\% PSA. NSCs were cultured in a humid incubator containing $5 \% \mathrm{CO}_{2}$ at $37{ }^{\circ} \mathrm{C}$, and the culture medium was refreshed every two days. DCDFs were irradiated with UV light for $24 \mathrm{~h}$ before inoculation of NSCs (cell density $4 \times 10^{4}$ cells $/$ film). The CCK-8 assay was used to evaluate the ability of cell proliferation on the thin film every day.

Time-lapse images were recorded by an $\mathrm{ASTEC}^{\circledR} \mathrm{CCM}-1.4 \mathrm{XZY} / \mathrm{CO}_{2}$ system (ASTEC CO., Ltd., Fukuoka, Japan) with a CCD camera mounted on a time-lapse microscope with a magnification ratio of $100: 1$. The temperature for all screens was maintained at $37^{\circ} \mathrm{C}$. The image collection time took place from $0 \mathrm{~h}$ to $24 \mathrm{~h}$ after a pre-incubation period of $3 \mathrm{~h}$.

\subsection{Gene Expression of Neural-Related Marker for NSCs on DCDFs}

The gene expression of NSCs was performed on DCDFs and control groups to observe the differentiation behavior of cells. The gene expression of neurological markers was analyzed by the KAPA SYBR Green qPCR kit through a quantitative reverse transcriptionpolymerase chain reaction (RT-PCR), and the data were collected by the StepOnePlus Real-Time PCR instrument (Applied Biosystems, Foster City, CA, USA). The neurological marker genes evaluated in this study were nestin, glial fibrillary acidic protein (GFAP), $\beta$-tubulin, and microtubule-associated protein 2 (MAP2). Glyceraldehyde 3-phosphate dehydrogenase (GAPDH) was used to standardize the gene expression levels in relative proportions.

\subsection{Evaluation of DAPU/CEC/DCP (DCD) Materials as a Conductive Coating}

Two methods were used to confirm that DCD materials may be employed as a polymer coating, including atmospheric plasma coating and overlay coating. The overlay coating 
was to directly coat the DCD precursor uniformly on the glass substrate. In the atmospheric plasma coating method, the surface of the substrate was first modified by scanning with air plasma, and then the DCD precursor was uniformly coated on the plasma-modified substrate. The plasma equipment was an open-air plasma system (Openair ${ }^{\circledR}$ ) developed by Plasmatreat (Steinhagen, Germany). The plasma temperature at the nozzle exit was $25{ }^{\circ} \mathrm{C}$ and the air pressure was $2.5 \mathrm{~kg} / \mathrm{cm}^{2}$. The frequency of plasma ejection was set to $21,000 \mathrm{~Hz}$. The substrate was placed at a distance of $150 \mathrm{~mm}$ from the nozzle and the scanning speed of the nozzle was $30 \mathrm{~cm} / \mathrm{min}$. All the samples were dried at room temperature.

\subsection{Statistical Analysis}

All experimental results in this study were independently performed with at least three replicates to rule out contingency. The statistical differences between the experimental groups were performed by applying the commercially available statistical software package GraphPad Prism 4 and performed by two-way ANOVA with Tukey's posthoc statistical testing. The quantitative data of this experiment are presented in the form of "mean \pm standard deviation". Data with $p$ values smaller than 0.05 represented those with statistical significance.

\section{Results and Discussion}

\subsection{Preparation and Optimization of DCDFs}

Conductive DCDFs were prepared by adding the precursors (CEC, DCP, and DAPU) in proper order into a mould and dried at $25^{\circ} \mathrm{C}$, as demonstrated in Figure 1 . The conductive DCDFs were expected as potential biocompatible conductive polymer coating materials (described later in Section 3.5). Various DCDFs were generated using different component ratios. The conductivity of DCDFs with different formulae was tested by the four-point probe. The roughness was evaluated using the profilometer. Results are summarized in Table 1. The conductivity of DCP-containing DCDFs, measured in the dried state, was significantly higher than the non-DCP-containing control film. Among the three DCDFs with different contents, DCDF2 showed the maximum value of conductivity $(2.83 \pm 0.17 \mathrm{mS} / \mathrm{cm})$. In terms of roughness, all groups demonstrated rough surfaces, especially the control group without DCP. After optimization, the conductive thin films selected for further studies were those containing $49.75 \mathrm{wt} \%$ DAPU, $49.75 \mathrm{wt} \% \mathrm{CEC}$, and $0.50 \mathrm{wt} \%$ DCP (i.e., DCDF2 in Table 1). The notable differences of properties before the current materials and the materials from drying the earlier hydrogel may be associated with the low glass transition temperature $\left(T_{\mathrm{g}}\right)$ of the soft segment of the materials. We hypothesize that when the components in DCDFs are crosslinked with the gradual removal of the moisture, the low $T_{\mathrm{g}}$ soft segment (PCL) of DAPU would migrate, resulting in chain entanglement and self-assembly among the nanoparticles. This entanglement and self-assembly of DAPU may give rise to lower steric hindrance and a higher crosslinking degree for the resulting films. In contrast, if the crosslinking occurs first as in the hydrogel, the steric barrier of the crosslinking network would interfere with the entanglement and self-assembly of PCL segments during the drying process. The less favorable microphase separation may also contribute to the brittleness of the dried hydrogel. Meanwhile, the adequate electrical conductivity remained under a dry state for regulating biological activities [34,35]. The different roughness between the control group and DCDFs could be attributed to the presence of DCP. The addition of the positively charged DCP may produce an ionic reaction with negatively charged CEC and negatively charged DAPU and facilitate the more homogeneous crosslinking for networks of DCDFs [36]. The control groups used in all the following experiments were the non-DCP-containing films. 


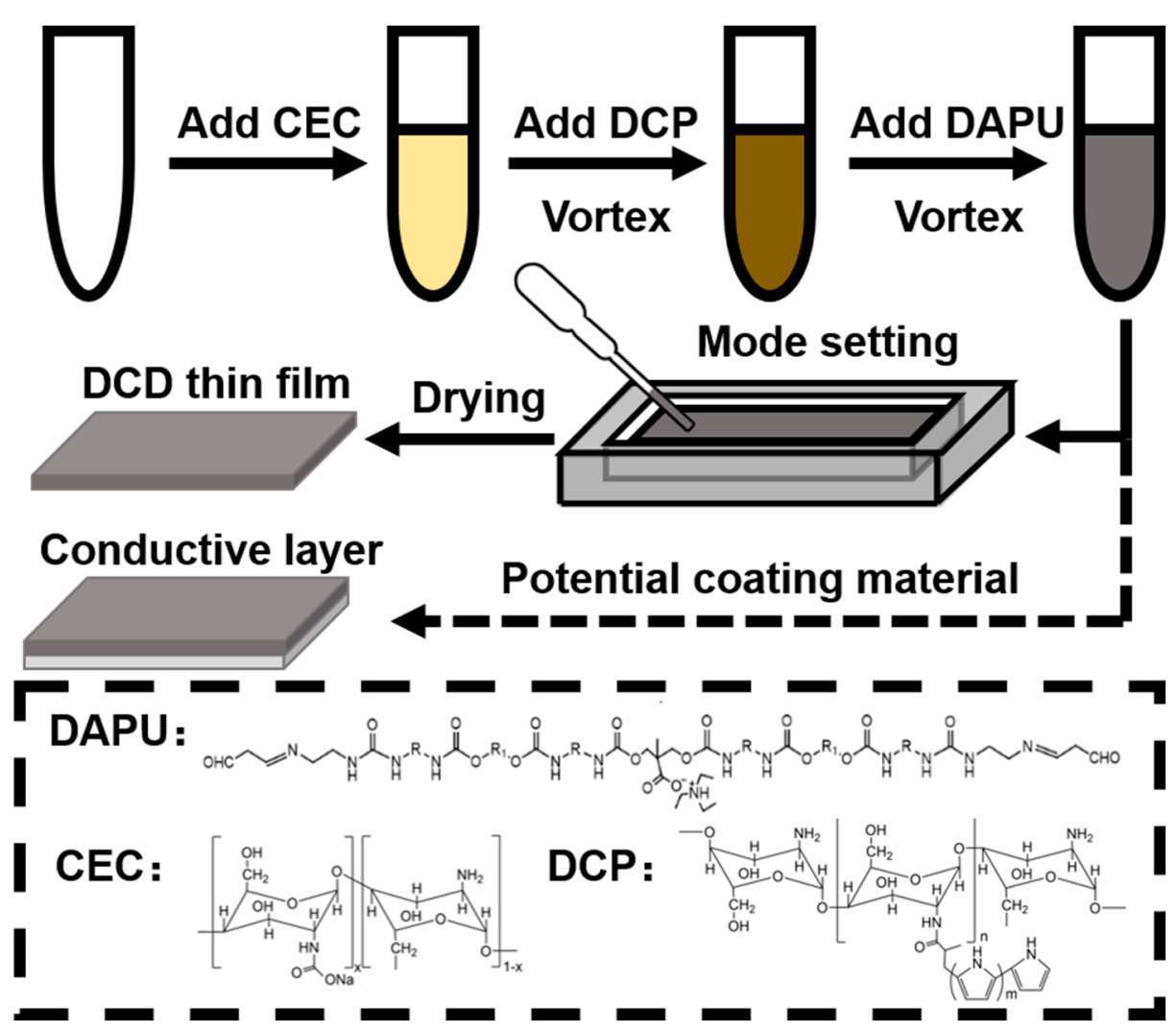

Figure 1. A schematic representation of the preparation process of the DAPU/CEC/DCP (DCD) thin films and their potential as biocompatible conductive polymer coating. DAPU: dialdehyde polyurethane; CEC: N-carboxyethyl chitosan; DCP: double-bonded chitosan modified polypyrrole.

Table 1. The basic properties and abbreviated names for the conductive DAPU/CEC/DCP (DCD) thin films (DCDFs) prepared with different formulae. DAPU: dialdehyde polyurethane; CEC: N-carboxyethyl chitosan; DCP: double-bonded chitosan modified polypyrrole.

\begin{tabular}{|c|c|c|c|c|c|}
\hline Abbreviation & DAPU/wt \% & CEC/wt \% & DCP/wt \% & Conductivity $/ \mathrm{mS} \cdot \mathrm{cm}^{-1}$ & 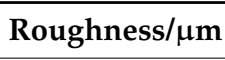 \\
\hline Control & 50.00 & 50.00 & 0 & $0.11 \pm 0.01$ & $7.94 \pm 0.54$ \\
\hline DCDF1 & 45.21 & 54.25 & 0.54 & $2.64 \pm 0.18$ & $8.05 \pm 0.36$ \\
\hline DCDF2 & 49.75 & 49.75 & 0.50 & $2.83 \pm 0.17$ & $7.94 \pm 0.23$ \\
\hline DCDF3 & 56.90 & 42.67 & 0.43 & $2.54 \pm 0.15$ & $8.40 \pm 0.28$ \\
\hline
\end{tabular}

The surface topography and hydrophilicity, related to the roughness of DCDFs [37], were further evaluated. SEM images of the control group confirmed its high surface roughness, consistent with the results obtained by the profilometer. SEM images of DCDFs and the control group showed in Figure 2 and Figure S1 (Supplementary Materials) revealed that all films were dense films (i.e., the surface and cross-section of films were non-porous). The DCDFs were two-dimensional substrate and did not possess a three-dimensional porous structure such as that of the cryogel or scaffold. Meanwhile, the DCDF1 showed a rougher surface than the other two DCDF groups due to the abundance of CEC in the system, which was consistent with the previous literature [38]. 


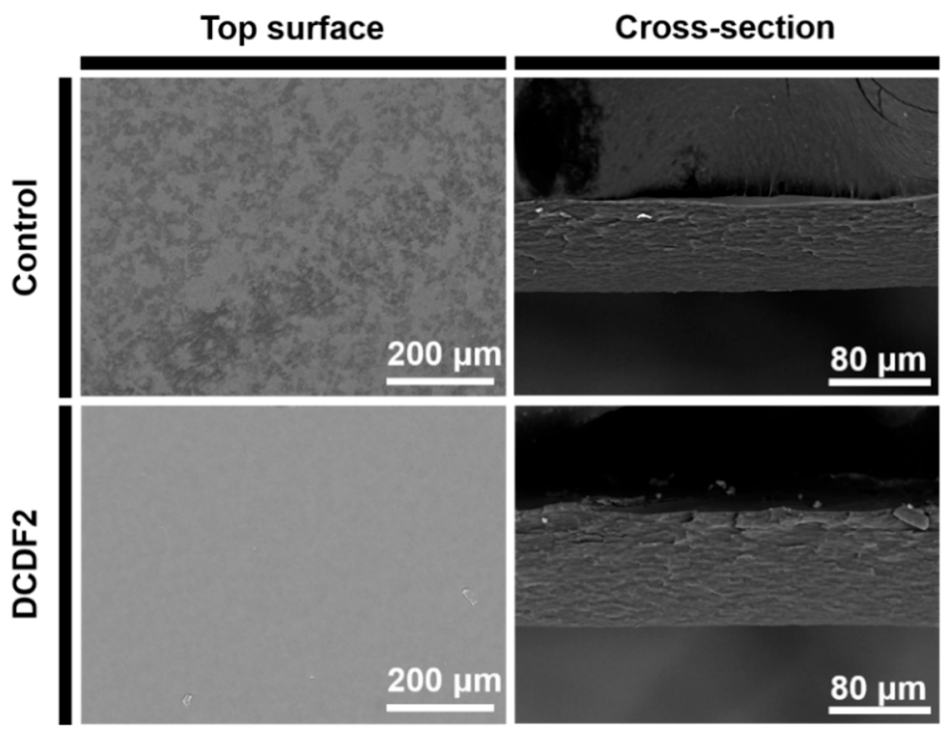

Figure 2. Scanning electron microscope (SEM) images of the control film and the DCDF film (DCDF2) in top-surface and cross-sectional views.

Analysis of the contact angle is one of the most established methods for investigating the surface properties of thin films. The contact angle takes into account the geometric measurement or the angle formed at the intersection of the liquid phase, gas phase, and solid phase, thus providing a direct evaluation of surface wettability [39]. The contact angle of water on the surface of DCDFs and the control group within the initial $60 \mathrm{~s}$ are shown in Figure 3. The contact angle of water on the surface of DCDFs dropped quickly from $\sim 63^{\circ}$ to around $27^{\circ}$, and the control group remained $\sim 40^{\circ}$ after $60 \mathrm{~s}$, which means there was about a $25 \%$ decrease in the water contact angle because of the DCP addition. Significant differences existed between the contact angle of water on the surface of DCDF2 and the other groups. The pure chitosan film had significantly greater contact angle values $\left(\sim 90^{\circ}\right)$ [40]. DCDF2 showed good hydrophilicity and had a low water contact angle $\left(25.4^{\circ}\right)$, close to that of the collagen surface [41]. These results showed that the conductive DCD materials may be a potential candidate for making hydrophilic conductive surface coatings.

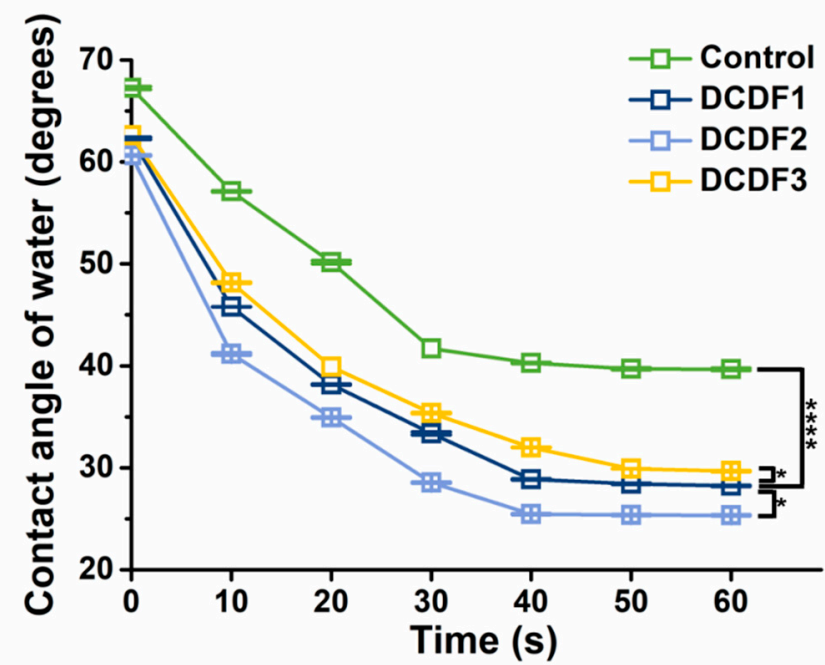

Figure 3. Water contact angles for the surface of the control group and different DCDFs as a function of time. The data points were an average of five test results. Control group: thin films without DCP. ${ }^{*} p<0.05$ and ${ }^{* * * *} p<0.0001$ between the indicated groups. 


\subsection{Physico-Chemical Properties of Conductive DCDFs}

The thermal properties of DCDFs and the control group were evaluated by TGA and DSC. Results are shown in Figure 4, with the melting temperatures, enthalpies, and crystallinity of DCDFs summarized in Table 2. The TGA curves in Figure 4A indicated that all the thin films were stable at high temperatures up to about $170^{\circ} \mathrm{C}$. All the curves for DCDFs showed a slower decay than that of the control group in the temperature range from $\sim 250{ }^{\circ} \mathrm{C}$ to $\sim 320^{\circ} \mathrm{C}$, indicating that the slower decay was contributed to by the presence of DCP (Figure S2, Supplementary Materials). The DSC results demonstrated that all the films had a prominent endothermic peak at $\sim 45^{\circ} \mathrm{C}$, probably associated with the crystallinity of PCL in the soft segment of the DAPU crosslinker [42]. There were two endothermic peaks (a small peak and a big sharp peak) between $140-160{ }^{\circ} \mathrm{C}$ in all films, probably associated with the crystallization of CEC [43]. The enthalpies of the control group, DCDF1, DCDF2, and DCDF3 from PCL were $11.03,3.26,8.86$, and $8.03 \mathrm{~J} / \mathrm{g}$, respectively. In addition, the enthalpies of the control group, DCDF1, DCDF2, and DCDF3 from chitosan were 10.13, $8.32,8.02$, and $7.44 \mathrm{~J} / \mathrm{g}$, respectively. Furthermore, the crystallinity of PCL and chitosan in the DCDFs was estimated based on the results of DSC curves. The crystallinity of PCL in each group (i.e., control group, DCDF1, DCDF2, and DCDF3) was $22.67 \%, 6.70 \%, 18.21 \%$, and $16.51 \%$, respectively. The crystallinity of CEC in each group was $10.71 \%, 8.80 \%, 8.48 \%$, and $7.87 \%$, respectively. The control group showed the highest enthalpy and crystallinity for either the PCL soft segments of DAPU or CEC in the absence of DCP that may interfere with crystallization. The crystallinity of CEC was reduced with the decrease of CEC content in the DCDF system. Among three DCDFs, DCDF2 displayed the highest enthalpy and crystallinity for PCL soft segments of DAPU and CEC, probably due to the appropriate degree of crosslinking in the whole system. PCL, as the only soft segment in the system, accounts for about $35 \mathrm{wt} \%$ of the whole system. The hard domains in this system include CEC, DCP, and a part of DAPU, which can lead to microphase separation in the dry state. The obvious crystallization behavior of PCL in DAPU may play an important role in affecting the mechanical properties of DCDFs. Therefore, the properties of the films below $\left(25^{\circ} \mathrm{C}\right)$ and above $\left(50^{\circ} \mathrm{C}\right)$ the PCL melting temperature (at $\left.\sim 47^{\circ} \mathrm{C}\right)$ were further evaluated by DMA to verify the temperature-dependent modulus changes of DCDFs.
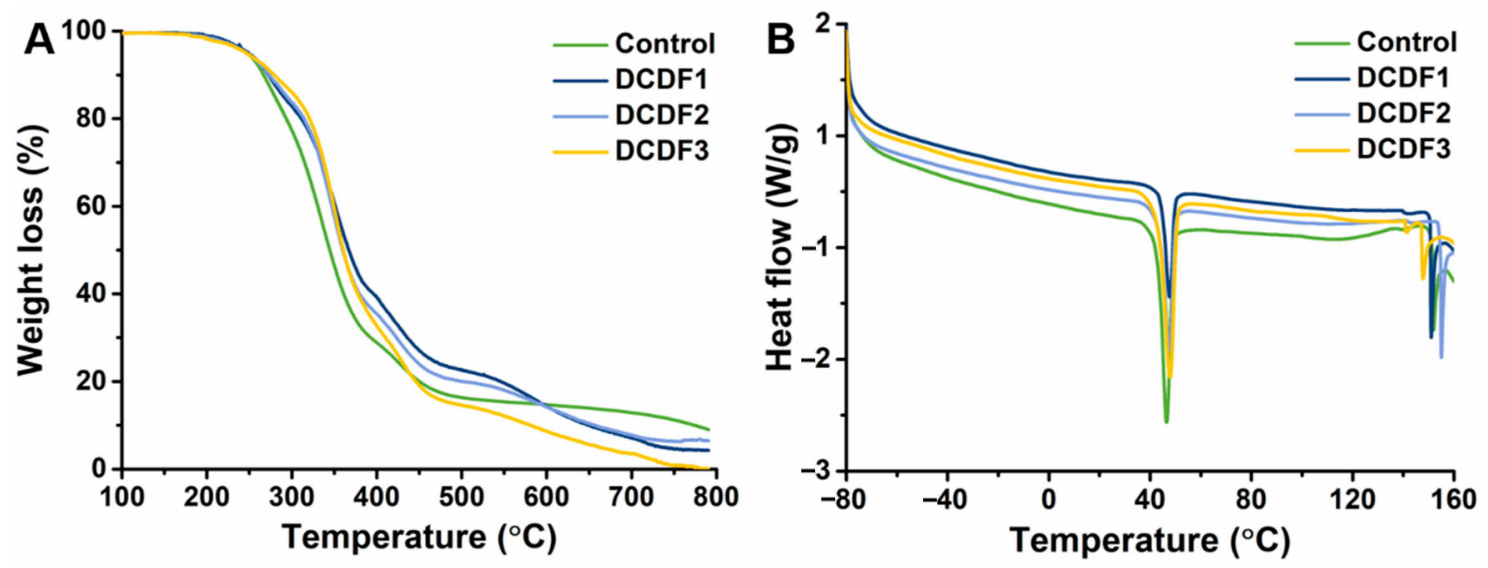

Figure 4. Thermal properties of the control group and DCDFs by (A) thermogravimetric analysis and (B) differential scanning calorimetry. Control group: thin films without DCP. 
Table 2. The detailed thermal properties of DCDFs summarized from differential scanning calorimetry (DSC) results.

\begin{tabular}{cccccccc}
\hline \multirow{2}{*}{ Samples } & \multicolumn{2}{c}{ Melting Temperature $\left(T_{\mathbf{m}}\right) /{ }^{\circ} \mathbf{C}$} & \multicolumn{2}{c}{ Enthalpy $\left(\Delta \boldsymbol{H}_{\mathbf{m}}\right) / \mathbf{J} \cdot \mathbf{g}^{-\mathbf{1}}$} & \multicolumn{2}{c}{ Crystallinity $\left(\boldsymbol{X}_{\mathrm{c}}\right)$} \\
\cline { 2 - 7 } & PCL & \multicolumn{2}{c}{ CEC } & PCL & CEC & PCL & CEC \\
\hline Control & 46.47 & 139.53 & 151.98 & 11.03 & 10.13 & $22.67 \%$ & $10.71 \%$ \\
DCDF1 & 47.72 & 142.65 & 151.07 & 3.26 & 8.32 & $6.70 \%$ & $8.80 \%$ \\
DCDF2 & 47.67 & 144.00 & 155.08 & 8.86 & 8.02 & $18.21 \%$ & $8.48 \%$ \\
DCDF3 & 47.90 & 141.25 & 147.76 & 8.03 & 7.44 & $16.51 \%$ & $7.87 \%$ \\
\hline
\end{tabular}

The elastic tensile modulus of DCDFs versus strain was evaluated by DMA under $25^{\circ} \mathrm{C}$ and $50{ }^{\circ} \mathrm{C}$, respectively, as shown in Figure 5A-D. All thin films were also subjected to static tensile tests under the dry condition to obtain the values of tensile strength and elongation at break under $25^{\circ} \mathrm{C}$ and $50{ }^{\circ} \mathrm{C}$, respectively, as shown in Figure 5E,F. The modulus of elasticity of the control, DCDF1, DCDF2, and DCDF3 at $25{ }^{\circ} \mathrm{C}$ were 2.18 MPa, 3.17 MPa, 1.73 MPa, and 2.26 MPa, respectively. After heating to $50{ }^{\circ} \mathrm{C}$, the modulus of elasticity in each group was decreased to a certain extent with the values of $1.83 \mathrm{MPa}, 2.78 \mathrm{MPa}, 1.52 \mathrm{MPa}$, and $1.79 \mathrm{MPa}$, possibly due to the melting of the soft segment (PCL). The data showed that addition of DCP improved the tensile break strength (from $8.67 \mathrm{MPa}$ to $9.72 \mathrm{MPa}$ ) and elongation (from $3.88 \%$ to $5.76 \%$ ) under $25^{\circ} \mathrm{C}$ in the two groups with the same proportion of DAPU and CEC (the control group and DCDF2, $\mathrm{m}_{\mathrm{CEC}}$ : $\left.m_{\text {DAPU }}=1: 1\right)$. At the same time, increasing the amount of DAPU in the case of DCDF2 and DCDF3 slightly increased the tensile properties of DCDFs. There were significant differences between each experimental result of DCDF2 and those of the control and the DCDF1 group. After heating, there also existed significant differences in the tensile break strength and elongation between DCDF2 and DCDF3. Since chitosan and its derivatives are brittle in the dry state, abundant CEC may cause phase separation in the dry DCDF. The tensile properties of such thin films may be lower due to stress concentration after stretching (as compared to DCDF1). Accordingly, unreacted DAPU, as an elastomer, may serve as a reinforcing agent to enhance the tensile properties of DCDFs below the PCL crystallization temperature. When the temperature was heated above the crystallization temperature of PCL $\left(\sim 50^{\circ} \mathrm{C}\right)$, the tensile break strength $(9.72 \mathrm{MPa}$ to $15.07 \mathrm{MPa})$ and the tensile elongation (from $5.76 \%$ to $12.77 \%$ ) of DCDF2 were obviously increased. Although the tensile properties of each group were improved at the higher temperature, DCDF2 remained to possess the best tensile properties at both $25^{\circ} \mathrm{C}$ and $50{ }^{\circ} \mathrm{C}$. $\mathrm{PCL}$, as the soft segment composition of DAPU, would soften when the temperature reached above $50{ }^{\circ} \mathrm{C}$, which enhanced the stretchability of DCDFs. The hard and soft segments of DAPU may undergo structure and phase rearrangement when the film was stretched, leading to the increase of tensile strength. The tensile properties of DCDF1 and DCDF3 were not as good as that of DCDF2, probably because the phase separation between the components was less favorable for rearrangement during the stretching process. Meanwhile, DCDF2 had the higher crystallinity of PCL segments than DCDF1 and DCDF3, which may also be the reason for better tensile properties after heating above $50^{\circ} \mathrm{C}$. 
A
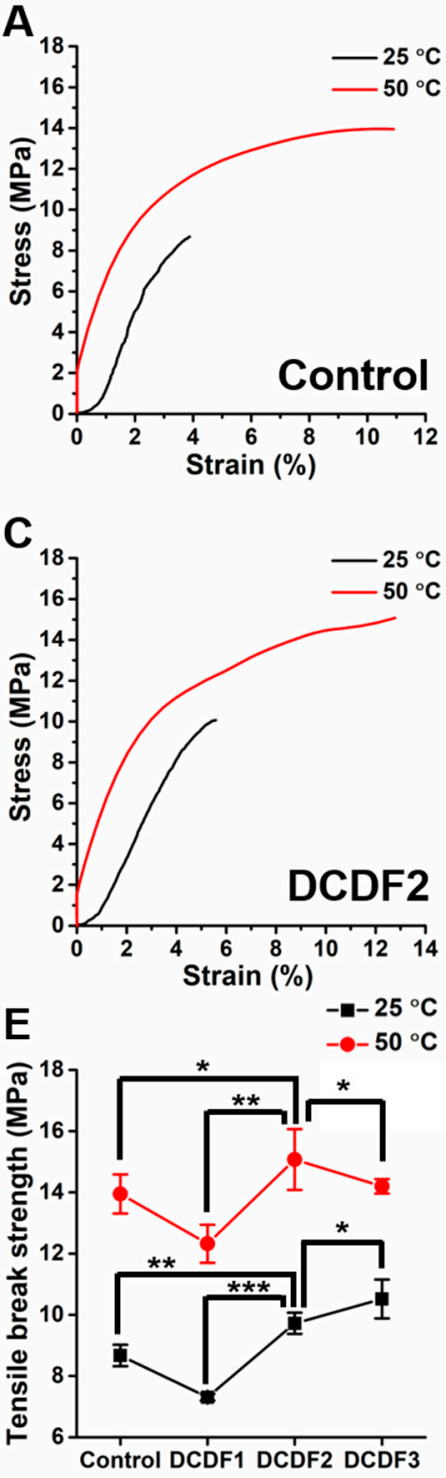

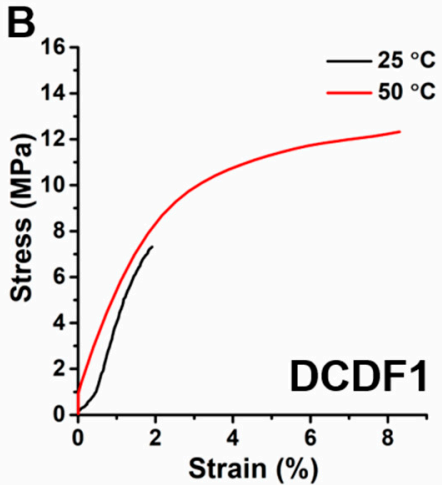

D
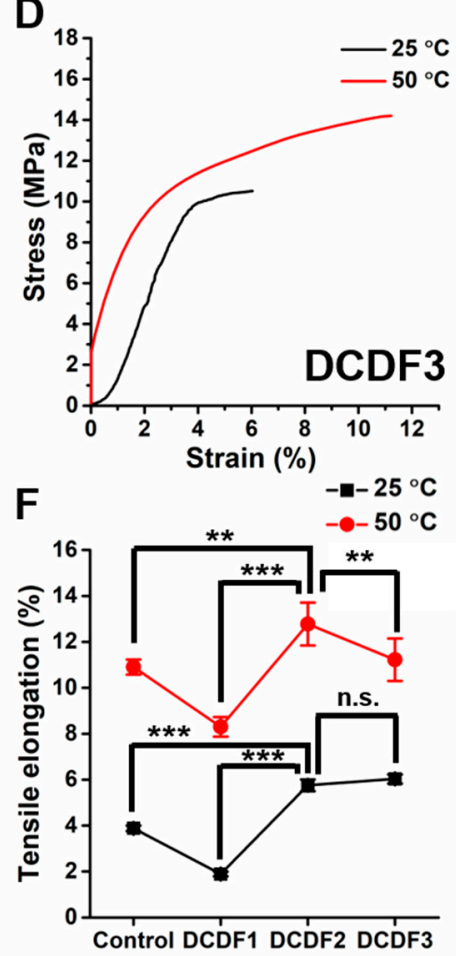

Figure 5. Tensile properties of DCDFs and the control group evaluated by DMA and a tensile tester under $25^{\circ} \mathrm{C}$ or $50^{\circ} \mathrm{C}$. (A-D) Tensile stress-strain curves of (A) the control group, (B) DCDF1, (C) DCDF2, and (D) DCDF3. Changes of (E) tensile break strength and (F) tensile elongation of all films. ${ }^{*} p<0.05,{ }^{* *} p<0.01$, and ${ }^{* * *} p<0.001$ between the indicated groups.

\subsection{Strain Sensing Functions of DCDFs}

The conductive DCDFs showed sensitivity to strains of various modes, including compression, twisting, and bending, as shown in Figure 6. The conductivity variation of the dried DCDFs was collected by a single-channel system source meter. The compressive strain was given by repeated loading of the weight $(50 \mathrm{~g})$. The conductivity variation of the film only slightly decreased after loading the weight $(\sim 0.1$ to $\sim 0.08)$. The response of DCDFs to compressive strain was not obvious, which may be limited by the thickness of the film. The conductivity variation was more obvious for the twisting mode (from $\sim 0.1$ to $\sim 0.36$ ) or the bending mode (from $\sim 0.1$ to $\sim 0.40$ ). The conductivity changes during the repeated deformation were all reproducible and reversible (i.e., returning to the initial value after strain removal) [44]. These data, together with the biocompatibility that will be discussed later, suggest the potential of DCDFs as wearable or implantable flexible human motion-detective sensors. 


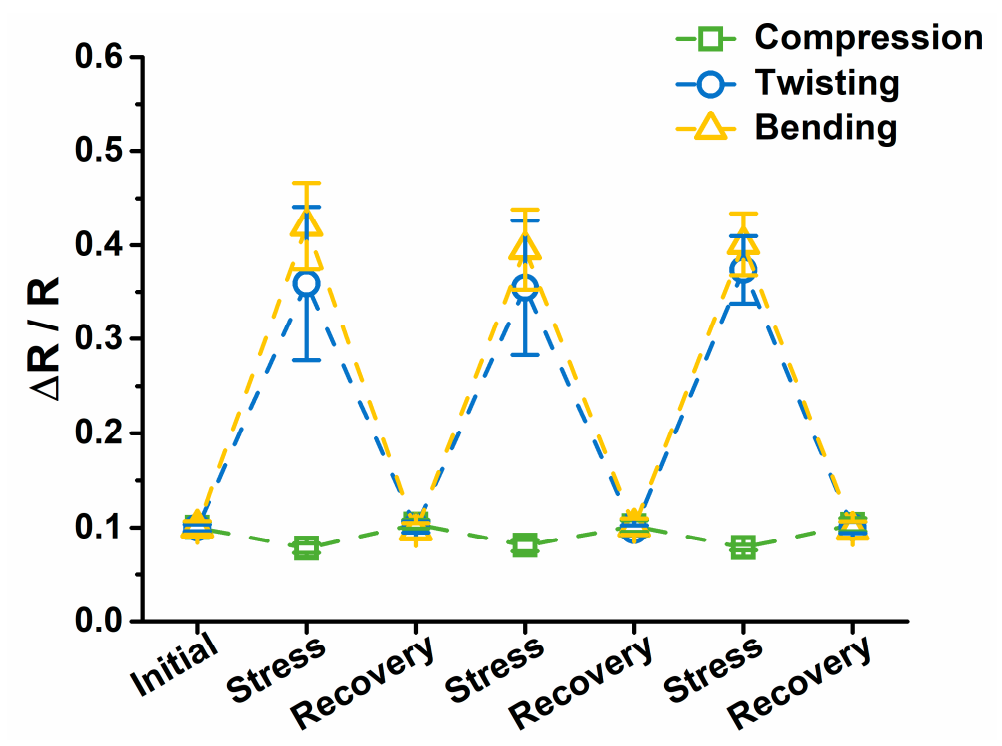

Figure 6. Sensing functions of DCDFs under $0.5 \mathrm{~V}$ of applied voltage. Changes of the thin film conductivity versus repeated loading weight of $50 \mathrm{~g}$, repeated twisting of $180^{\circ}$, and repeated bending of $90^{\circ}$. Data were obtained from DCDF2.

\subsection{Cell Morphology, Proliferation, and Differentiation of NSCs on DCDFs}

To confirm NSCs were attached on DCDFs, the cell morphology of NSCs after preincubation for $3 \mathrm{~h}$ was constantly monitored using time-lapse recording. During the 24-h recording, NSCs were found to attach on both DCDFs and the control group (Figure 7) with continuous changes of cell morphology (Movie S1, Supplementary Materials). Meanwhile, the recording showed that NSCs on DCDFs had obvious clustering behavior after $4 \mathrm{~h}$ and tended to develop into multicellular spheroids, but this clustering phenomenon was not seen in the control group. The multicellular spheroids of NSCs have been reported to mimic the neurospheres and may favor neural differentiation $[24,45]$.

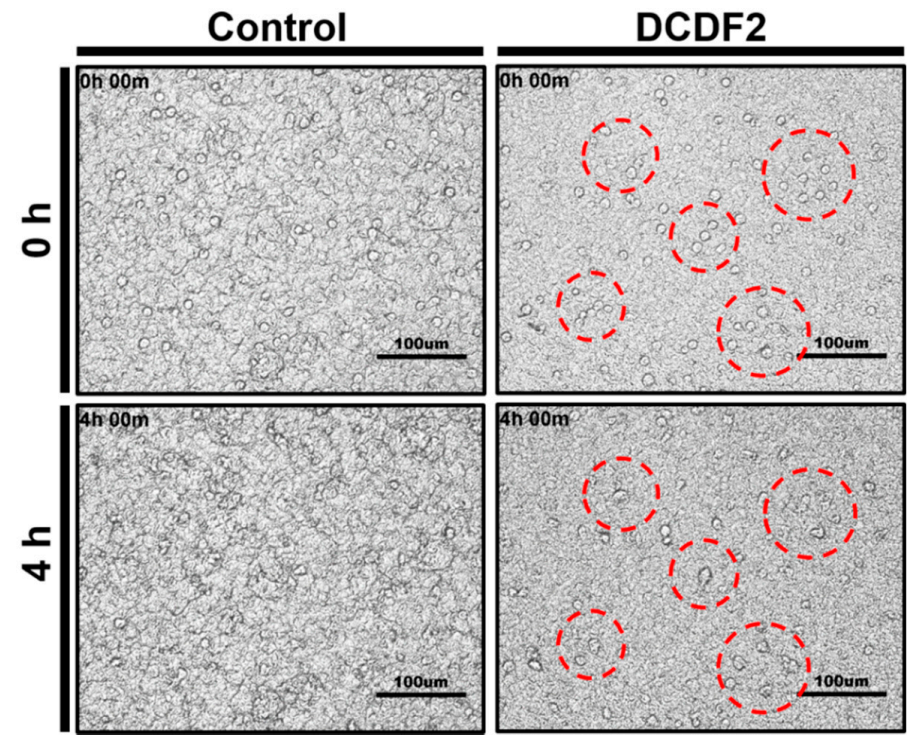

Figure 7. The morphology of neural stem cells (NSCs) seeded on DCDFs examined using time-lapse recording after pre-incubation for $3 \mathrm{~h}$. NSCs were seeded in 12-well plates $\left(4 \times 10^{5} \mathrm{NSC}\right.$ per well) coated with DCDFs or the control group. The NSCs on DCDFs had obvious aggregation behavior after $4 \mathrm{~h}$, indicated by red circles. Data were obtained from DCDF2. Control group: thin films without DCP. 
Proliferation of NSCs on DCDFs in a period of 4 days was compared with the control group. The data were obtained using the CCK-8 assay, as shown in Figure 8. After 4 days, the cell viability was $\sim 329.3 \%$ and $\sim 283.7 \%$ for DCDF2 and the control group (without DCP), respectively. On the other hand, the cell viability on DCDF1 and DCDF3 was $\sim 231.9 \%$ and $\sim 288.0 \%$ at 4 days, lower than that on the DCDF2 ( 329.3\%). There were significantly differences in the viability of NSCs on DCDF2 from the other groups at 4 days.

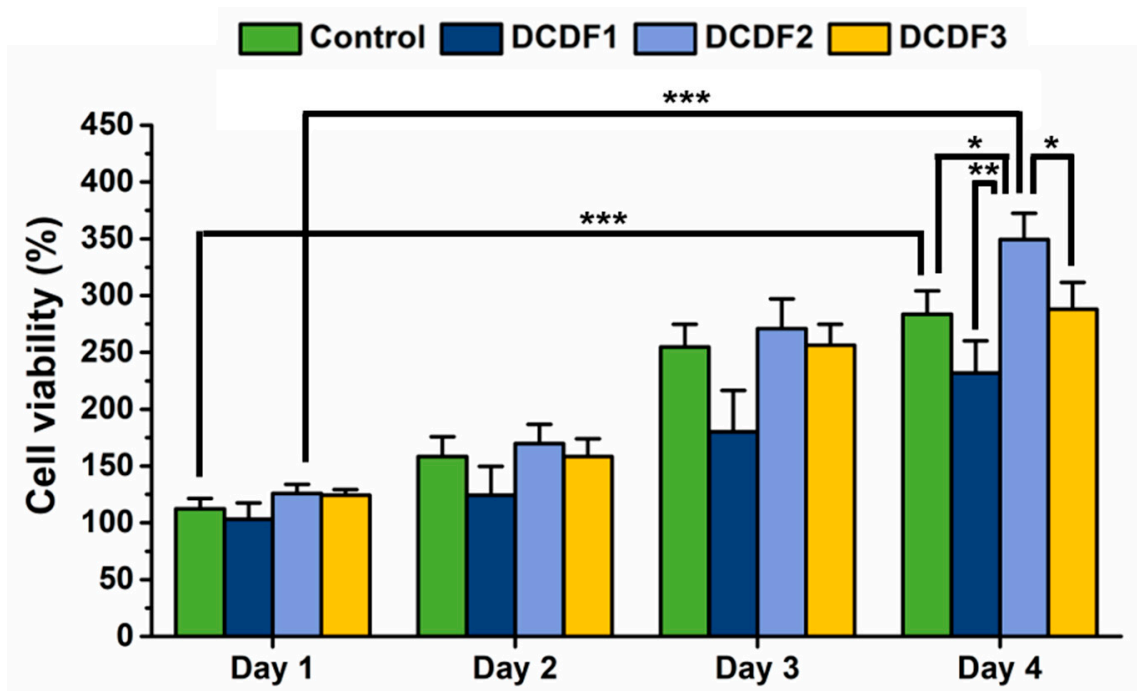

Figure 8. The proliferation of neural stem cells (NSCs) on DCDFs in a period of 4 days compared with the control group (cells on the thin film without DCP). The data were obtained using the CCK-8 assay. The viability of NSCs was deducted from that of the blank group (the same thin films without cells), normalized to the value at day 0 , and expressed as the percentage of cell viability $(\%) .{ }^{*} p<0.05$, ** $p<0.01$, and ${ }^{* * *} p<0.001$ between the indicated groups.

The gene expression of NSCs was performed on DCDFs and the non-DCP-containing control after 4 days to verify the cell differentiation behavior. The expression of neuralrelated genes, including nestin, GFAP, $\beta$-tubulin, and MAP2, is displayed in Figure 9, where the expression was normalized to GAPDH gene and then expressed in relative proportions. The expression levels of nestin (stemness marker), $\beta$-tubulin (early neuronal marker), and MAP2 (mature neuronal marker) genes after 4 days showed no significant differences between the DCDFs and the control group. In contrast, the expression level of the GFAP (glial marker) gene was significantly upregulated for NSCs on DCDF2 after 4 days as compared to the control group, but there was no significant difference among the control, DCDF1, and DCDF3. According to previous literature [46,47], chitosan-based materials promoted the survival of stem cells and neurite extension owing to the degradation products of chitosan. Compared to the conductive hydrogel [28], two-dimensional conductive DCDFs for 4 days seemed to promote the expression of the GFAP gene only, but not the other three related genes. The finding agreed with the literature reporting that two-dimensional polypyrrole-containing conductive films promoted the expression of glialrelated genes (i.e., GFAP) more than the neuronal-related genes [48]. Taken together, these data suggested that DCDFs facilitated the aggregation, proliferation, and differentiation of NSCs, especially the DCDF2. 

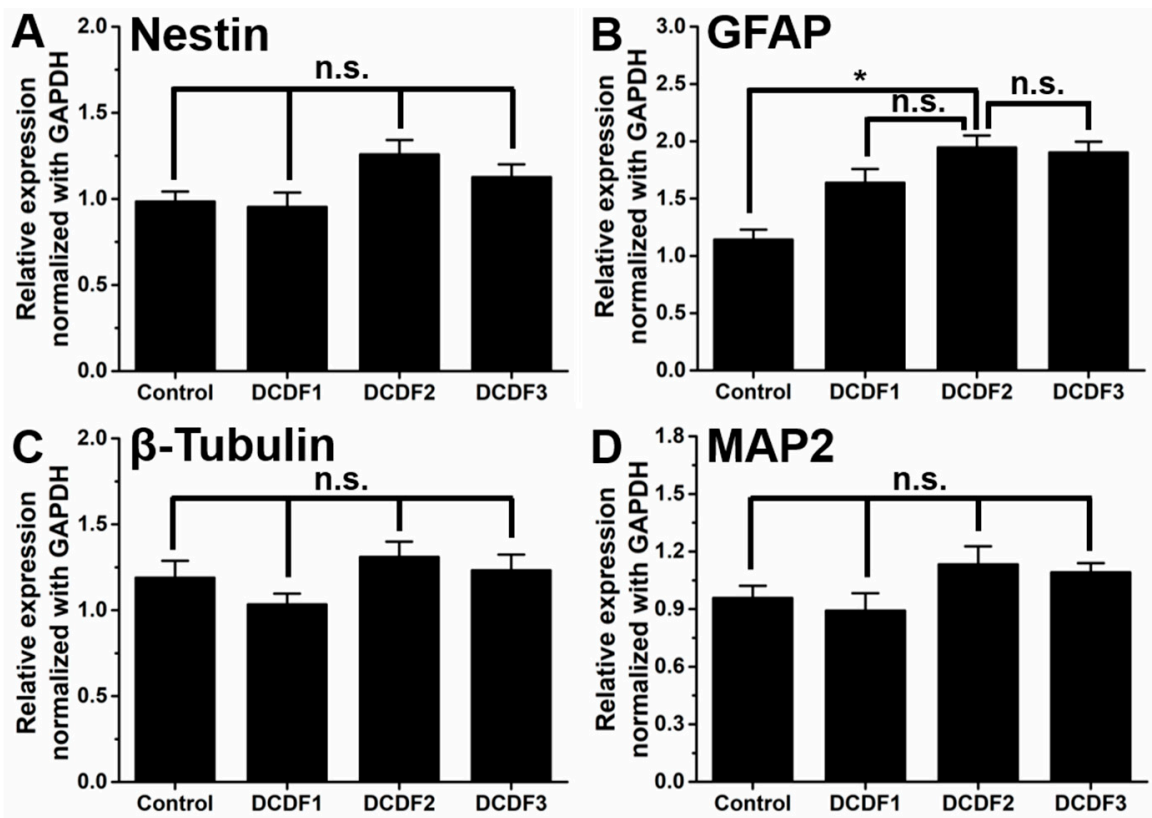

Figure 9. The differentiation of NSCs on DCDFs. The gene expressions of neural-related genes, including (A) Nestin, (B) GFAP, (C) $\beta$-tubulin, and (D) MAP2, were analyzed by RT-PCR at 4 days. The expression levels are represented by the relative ratios of gene expression normalized to that of GAPDH. ${ }^{*} p<0.05$ between the indicated groups. Control group: thin films without DCP.

\subsection{The Potential as Conductive Coating Materials}

The potential of DCDFs employed as a polymer coating layer was demonstrated by two commonly used coating methods, including atmospheric plasma coating and overlay coating, as shown in Figure S3 (Supplementary Materials). As a coating material, the appropriate viscosity before coating and homogeneity after coating should be considered. Most published chitosan-based hydrogels cannot be dried and used as thin films due to their brittleness and excessive phase separation in the dry state. Because of the difficulty in coating chitosan-based hydrogels and casting them as dried films, not much research has been conducted on the related topic. DCD precursors, with adequate viscosity and homogeneity, are expected to have coating applications and produce multifunctional dried thin films. To start with, DCD materials were preliminarily coated on the 12-well plates to investigate the cell proliferation and differentiation (described in Section 3.4). In addition, some conventional coating methods (i.e., atmospheric plasma coating and overlay coating) were used to evaluate the potential as a conductive hydrophilic biocompatible coating material. The results showed that DCD materials can effectively and uniformly modify the surface of the substrate. Meanwhile, with reference to all above characteristics, the surface modification with DCD materials can endow both conductivity and hydrophilicity to the substrate, as well as enhance the cellular compatibility. This conductive DCD thin film/coating, to the best of our knowledge, is the first report on multifunctional film materials with hydrophilicity, thermal responsiveness, strain sensing, and biocompatibility, suggesting a promising surface coating candidate for biomedical applications.

\section{Conclusions}

Thermoresponsive and conductive thin films composed of DAPU, CEC, and DCP were successfully synthesized and prepared. The tri-component DCDFs showed hydrophilicity and densification. These thin films exhibited adequate conductivity (all above $2.50 \mathrm{mS} / \mathrm{cm}$ ) in a dry state. Thermoresponsive tensile properties, i.e., tensile break strength (an increase from 9.72 $\mathrm{MPa}$ to $15.07 \mathrm{MPa}$ ) and tensile elongation (an increase from $5.76 \%$ to $12.77 \%$ ), were verified by DMA under $25^{\circ} \mathrm{C}$ or $50^{\circ} \mathrm{C}$. The potential for strain sensing was demonstrated by the relative changes of conductivity in response to the deformation of various 
modes. Besides, NSCs seeded on the surface of DCDFs showed greater cell proliferation and differentiation than those on non-conductive controls. Moreover, DCD materials may serve as a polymer coating. These findings suggested that thermoresponsive and conductive DCDFs developed in this study may be potential films and possible coating with hydrophilicity, thermal responsiveness, strain sensing, and biocompatibility.

Supplementary Materials: The following are available online at https:/ /www.mdpi.com/2073-436 0/13/3/326/s1. Figure S1: SEM images of DCDF1 and DCDF3 in top surface and cross-sectional view. Figure S2: The TGA curve of DCP. Figure S3: Testing of DCDFs as a potential coating. Movie S1: Cell morphology. Continuous changes of cell morphology and the movement of NSCs on the DCD thin film within $24 \mathrm{~h}$.

Author Contributions: Conceptualization, S.-h.H. and J.X.; methodology, S.-h.H., J.X., C.-Y.F., Y.-L.T. and C.-W.W.; validation, C.-Y.F. and Y.-L.T.; formal analysis, C.-Y.F., Y.-L.T., C.-W.W.; data curation, J.X.; writing—original draft preparation, S.-h.H., J.X., C.-Y.F., Y.-L.T. and C.-W.W.; writing-review and editing, S.-h.H., J.X. and C.-W.W.; supervision, S.-h.H. All authors have read and agreed to the published version of the manuscript.

Funding: This work was supported by the Ministry of Science and Technology (MOST 108-2221-E002-082-MY3), Taiwan, and partially supported by National Taiwan University (NTU-CC-109L891001).

Institutional Review Board Statement: Not applicable.

Informed Consent Statement: Not applicable.

Data Availability Statement: Data sharing is not applicable to this article.

Conflicts of Interest: The authors declare no conflict of interest.

\section{References}

1. Nezakati, T.; Seifalian, A.; Tan, A.; Seifalian, A.M. Conductive Polymers: Opportunities and Challenges in Biomedical Applications. Chem. Rev. 2018, 118, 6766-6843. [CrossRef] [PubMed]

2. Xu, J.; Tsai, Y.-L.; Hsu, S.-h. Design Strategies of Conductive Hydrogel for Biomedical Applications. Molecules 2020, 25, 5296. [CrossRef] [PubMed]

3. Noreen, A.; Zia, K.M.; Zuber, M.; Tabasum, S.; Zahoor, A.F. Bio-based polyurethane: An efficient and environment friendly coating systems: A review. Prog. Org. Coat. 2016, 91, 25-32. [CrossRef]

4. Zhou, Y.; Azumi, R.; Shimada, S. A highly durable, stretchable, transparent and conductive carbon nanotube-polymeric acid hybrid film. Nanoscale 2019, 11, 3804-3813. [CrossRef] [PubMed]

5. Avcu, E.; Baştan, F.E.; Abdullah, H.Z.; Rehman, M.A.U.; Avcu, Y.Y.; Boccaccini, A.R. Electrophoretic deposition of chitosan-based composite coatings for biomedical applications: A review. Prog. Mater. Sci. 2019, 103, 69-108. [CrossRef]

6. Kim, S.; Jang, L.K.; Park, H.S.; Lee, J.Y. Electrochemical deposition of conductive and adhesive polypyrrole-dopamine films. Sci. Rep. 2016, 6, 1-8. [CrossRef]

7. Lam, J.Y.; Shih, C.C.; Lee, W.Y.; Chueh, C.C.; Jang, G.W.; Huang, C.J.; Tung, S.H.; Chen, W.C. Bio-Based Transparent Conductive Film Consisting of Polyethylene Furanoate and Silver Nanowires for Flexible Optoelectronic Devices. Macromol. Rapid Commun. 2018, 39, 1800271. [CrossRef]

8. Black, B.J.; Ecker, M.; Stiller, A.; Rihani, R.; Danda, V.R.; Reed, I.; Voit, W.E.; Pancrazio, J.J. In vitro compatibility testing of thiol-ene/acrylate-based shape memory polymers for use in implantable neural interfaces. J. Biomed. Mater. Res. Part A 2018, 106, 2891-2898. [CrossRef]

9. Wu, J.-G.; Chen, J.-H.; Liu, K.-T.; Luo, S.-C. Engineering antifouling conducting polymers for modern biomedical applications. ACS Appl. Mater. Interfaces 2019, 11, 21294-21307. [CrossRef]

10. Zhou, B.; Su, M.; Yang, D.; Han, G.; Feng, Y.; Wang, B.; Ma, J.; Ma, J.; Liu, C.; Shen, C. Flexible MXene/Silver Nanowire-Based Transparent Conductive Film with Electromagnetic Interference Shielding and Electro-Photo-Thermal Performance. ACS Appl. Mater. Interfaces 2020, 12, 40859-40869. [CrossRef]

11. Hsu, S.-h.; Chen, W.-C. Improved cell adhesion by plasma-induced grafting of l-lactide onto polyurethane surface. Biomaterials 2000, 21, 359-367. [CrossRef]

12. Xu, J.; McCarthy, S.P.; Gross, R.A.; Kaplan, D.L. Chitosan Film Acylation and Effects on Biodegradability. Macromolecules 1996, 29, 3436-3440. [CrossRef]

13. Joshi, M.; Adak, B.; Butola, B. Polyurethane nanocomposite based gas barrier films, membranes and coatings: A review on synthesis, characterization and potential applications. Prog. Mater. Sci. 2018, 97, 230-282. [CrossRef]

14. Yang, H.; Yu, B.; Song, P.; Maluk, C.; Wang, H. Surface-coating engineering for flame retardant flexible polyurethane foams: A critical review. Compos. Part B Eng. 2019, 176, 107185. [CrossRef] 
15. Thangavelu, S.A.G.; Murali, A.; Sharanya, M.; Jaisankar, S.N.; Mandal, A.B. Studies on biodegradable polyurethane-SWCNTs nanocomposite films by covalent approach: Physicochemical, electric and mechanical properties. Appl. Surf. Sci. 2018, 449, 745754. [CrossRef]

16. Zhu, H.; Yang, Y.; Sheng, A.; Duan, H.; Zhao, G.; Liu, Y. Layered structural design of flexible waterborne polyurethane conductive film for excellent electromagnetic interference shielding and low microwave reflectivity. Appl. Surf. Sci. 2019, 469, 1-9. [CrossRef]

17. Lee, T.-H.; Yen, C.-T.; Hsu, S.-H. Preparation of polyurethane-graphene nanocomposite and evaluation of neurovascular regeneration. ACS Biomater. Sci. Eng. 2020, 6, 597-609. [CrossRef]

18. Ou, C.-W.; Su, C.-H.; Jeng, U.-S.; Hsu, S.-h. Characterization of biodegradable polyurethane nanoparticles and thermally induced self-assembly in water dispersion. ACS Appl. Mater. Interfaces 2014, 6, 5685-5694. [CrossRef]

19. Hsiao, S.-H.; Hsu, S.-H. Synthesis and characterization of dual stimuli-sensitive biodegradable polyurethane soft hydrogels for 3D cell-laden bioprinting. ACS Appl. Mater. Interfaces 2018, 10, 29273-29287. [CrossRef]

20. Lin, T.-W.; Hsu, S.-H. Self-Healing Hydrogels and Cryogels from Biodegradable Polyurethane Nanoparticle Crosslinked Chitosan. Adv. Sci. 2020, 7, 1901388. [CrossRef]

21. Shi, Z.; Gao, X.; Ullah, M.W.; Li, S.; Wang, Q.; Yang, G. Electroconductive natural polymer-based hydrogels. Biomaterials 2016, 111, 40-54. [CrossRef] [PubMed]

22. Xu, J.; Liu, Y.; Hsu, S.-h. Hydrogels Based on Schiff Base Linkages for Biomedical Applications. Molecules 2019, 24,3005 [CrossRef] [PubMed]

23. Qu, J.; Zhao, X.; Liang, Y.; Xu, Y.; Ma, P.X.; Guo, B. Degradable conductive injectable hydrogels as novel antibacterial, anti-oxidant wound dressings for wound healing. Chem. Eng. J. 2019, 362, 548-560. [CrossRef]

24. Tseng, T.-C.; Tao, L.; Hsieh, F.-Y.; Wei, Y.; Chiu, I.-M.; Hsu, S.-h. An injectable, self-healing hydrogel to repair the central nervous system. Adv. Mater. 2015, 27, 3518-3524. [CrossRef] [PubMed]

25. Banerjee, S.; Bagchi, B.; Bhandary, S.; Kool, A.; Hoque, N.A.; Biswas, P.; Pal, K.; Thakur, P.; Das, K.; Karmakar, P. Antimicrobial and biocompatible fluorescent hydroxyapatite-chitosan nanocomposite films for biomedical applications. Colloids Surf. B Biointerfaces 2018, 171, 300-307. [CrossRef] [PubMed]

26. Huang, J.; Qin, J.; Zhang, P.; Chen, X.; You, X.; Zhang, F.; Zuo, B.; Yao, M. Facile preparation of a strong chitosan-silk biocomposite film. Carbohydr. Polym. 2020, 229, 115515. [CrossRef]

27. Kenry; Liu, B. Recent advances in biodegradable conducting polymers and their biomedical applications. Biomacromolecules 2018, 19, 1783-1803. [CrossRef]

28. Xu, J.; Wong, C.-W.; Hsu, S.-H. An Injectable, Electroconductive Hydrogel/Scaffold for Neural Repair and Motion Sensing Chem. Mater. 2020, 32, 10407-10422. [CrossRef]

29. Lin, Y.-J.; Chuang, W.-T.; Hsu, S.-H. Gelation mechanism and structural dynamics of chitosan self-healing hydrogels by in situ SAXS and coherent X-ray scattering. ACS Macro Lett. 2019, 8, 1449-1455. [CrossRef]

30. Darabi, M.A.; Khosrozadeh, A.; Mbeleck, R.; Liu, Y.; Chang, Q.; Jiang, J.; Cai, J.; Wang, Q.; Luo, G.; Xing, M. Skin-Inspired multifunctional autonomic-intrinsic conductive self-healing hydrogels with pressure sensitivity, stretchability, and $3 \mathrm{D}$ printability. Adv. Mater. 2017, 29, 1700533. [CrossRef]

31. Patricio, T.; Bártolo, P. Thermal stability of PCL/PLA blends produced by physical blending process. Procedia Eng. 2013, 59, 292-297. [CrossRef]

32. Woodruff, M.A.; Hutmacher, D.W. The return of a forgotten polymer-Polycaprolactone in the 21st century. Prog. Polym. Sci. 2010, 35, 1217-1256. [CrossRef]

33. Deng, Z.; Guo, Y.; Zhao, X.; Ma, P.X.; Guo, B. Multifunctional stimuli-responsive hydrogels with self-healing, high conductivity, and rapid recovery through host-guest interactions. Chem. Mater. 2018, 30, 1729-1742. [CrossRef]

34. Sun, B.; Wu, T.; Wang, J.; Li, D.; Wang, J.; Gao, Q.; Bhutto, M.A.; El-Hamshary, H.; Al-Deyab, S.S.; Mo, X. Polypyrrole-coated poly(l-lactic acid-co- $\varepsilon$-caprolactone)/silk fibroin nanofibrous membranes promoting neural cell proliferation and differentiation with electrical stimulation. J. Mater. Chem. B 2016, 4, 6670-6679. [CrossRef]

35. Bu, Y.; Xu, H.-X.; Li, X.; Xu, W.-J.; Yin, Y.-X.; Dai, H.-1.; Wang, X.-b.; Huang, Z.-J.; Xu, P.-H. A conductive sodium alginate and carboxymethyl chitosan hydrogel doped with polypyrrole for peripheral nerve regeneration. RSC Adv. 2018, 8, 10806-10817. [CrossRef]

36. Fu, B.; Cheng, B.; Bao, X.; Wang, Z.; Shangguan, Y.; Hu, Q. Self-healing and conductivity of chitosan-based hydrogels formed by the migration of ferric ions. J. Appl. Polym. Sci. 2019, 136, 47885. [CrossRef]

37. Guo, Y.; Bae, J.; Fang, Z.; Li, P.; Zhao, F.; Yu, G. Hydrogels and Hydrogel-Derived Materials for Energy and Water Sustainability. Chem. Rev. 2020, 120, 7642-7707. [CrossRef]

38. Xie, H.G.; Zheng, J.N.; Li, X.X.; Liu, X.D.; Zhu, J.; Wang, F.; Xie, W.Y.; Ma, X.J. Effect of Surface Morphology and Charge on the Amount and Conformation of Fibrinogen Adsorbed onto Alginate/Chitosan Microcapsules. Langmuir 2010, 26, 5587-5594. [CrossRef]

39. Zhang, W.; Li, G.; Fang, Y.; Wang, X. Maleic anhydride surface-modification of crosslinked chitosan membrane and its pervaporation performance. J. Membr. Sci. 2007, 295, 130-138. [CrossRef]

40. Chen, T.W.; Chang, S.J.; Niu, G.C.-C.; Hsu, Y.T.; Kuo, S.M. Alginate-coated chitosan membrane for guided tissue regeneration. J. Appl. Polym. Sci. 2006, 102, 4528-4534. [CrossRef] 
41. Fu, W.; Liu, Z.; Feng, B.; Hu, R.; He, X.; Wang, H.; Yin, M.; Huang, H.; Zhang, H.; Wang, W. Electrospun gelatin/PCL and collagen/PLCL scaffolds for vascular tissue engineering. Int. J. Nanomed. 2014, 9, 2335. [CrossRef] [PubMed]

42. Chien, Y.-c.; Chuang, W.-T.; Jeng, U.-S.; Hsu, S.-H. Preparation, characterization, and mechanism for biodegradable and biocompatible polyurethane shape memory elastomers. ACS Appl. Mater. Interfaces 2017, 9, 5419-5429. [CrossRef] [PubMed]

43. Kumirska, J.; Czerwicka, M.; Kaczyński, Z.; Bychowska, A.; Brzozowski, K.; Thöming, J.; Stepnowski, P. Application of spectroscopic methods for structural analysis of chitin and chitosan. Mar. Drugs 2010, 8, 1567-1636. [CrossRef] [PubMed]

44. Trung, T.Q.; Dang, T.M.L.; Ramasundaram, S.; Toi, P.T.; Park, S.Y.; Lee, N.-E. A Stretchable Strain-Insensitive Temperature Sensor Based on Free-Standing Elastomeric Composite Fibers for On-Body Monitoring of Skin Temperature. Acs Appl. Mater. Interfaces 2019, 11, 2317-2327. [CrossRef] [PubMed]

45. Hsu, S.-h.; Lin, Y.; Lin, T.-C.; Tseng, T.-C.; Lee, H.-T.; Liao, Y.-C.; Chiu, I.-M. Spheroid formation from neural stem cells on chitosan membranes. J. Med. Biol. Eng. 2012, 32, 85-90. [CrossRef]

46. Ren, Y.-J.; Zhang, H.; Huang, H.; Wang, X.-M.; Zhou, Z.-Y.; Cui, F.-Z.; An, Y.-H. In vitro behavior of neural stem cells in response to different chemical functional groups. Biomaterials 2009, 30, 1036-1044. [CrossRef]

47. Yang, Y.; Liu, M.; Gu, Y.; Lin, S.; Ding, F.; Gu, X. Effect of chitooligosaccharide on neuronal differentiation of PC-12 cells. Cell Biol. Int. 2009, 33, 352-356. [CrossRef]

48. Stewart, E.; Kobayashi, N.R.; Higgins, M.J.; Quigley, A.F.; Jamali, S.; Moulton, S.E.; Kapsa, R.M.I.; Wallace, G.G.; Crook, J.M. Electrical stimulation using conductive polymer polypyrrole promotes differentiation of human neural stem cells: A biocompatible platform for translational neural tissue engineering. Tissue Eng. Part C Methods 2015, 21, 385-393. [CrossRef] 